\title{
“Little Red Sandals": Female Police Officers' Lived Experience of Investigating Sexual Violence
}

Keywords

Gender; Police officers; Sexual violence; Secondary traumatic stress; Vicarious

trauma; Organisational support

Abstract

Purpose

Against a background of increasing workload and external criticism, this paper exposes the indelible memories impressed on female police officers dedicated to investigating allegations of rape and sexual violence.

Design

Participants $(\mathrm{N}=15)$ were female police officers working in a specialist sexual offences investigation unit in a large English Metropolitan Police Force. A semistructured interview was employed to elicit their experiences as an example of 'extreme' police work. Interpretative Phenomenological Analysis (IPA) was used to develop themes elucidating psychological and physical impacts on officers and their coping strategies.

\section{Findings}

Personal consequences were framed within the conceptualisation of secondary trauma. Emergent findings converged with previous studies on burnout and vicarious traumatisation. Under the theme 'the ailing self' participants reported feelings of depression, anxiety, suicidal ideation, intrusive imagery, altered beliefs and cognitions as well as disrupted intimacy with partners. Coping adaptations included sensory shutdown, avoidance, dissociation and a reduction in victim care.

Practical implications

The findings support the need to consider occupational interventions to address risk factors associated with caseload, tenure, personal experience of neglect (e.g. in childhood), and the permeability of work and family boundaries for such exceptional policing tasks.

Originality/value

The paper contributes to a nascent literature on specific sources of stress in 'extreme' police work. Our theoretical contribution is the focus on the emotional and physical aspects of vicarious trauma, which have been less well understood than cognitive aspects Our practice implications stress the need for targeted support activities given the profound psychological consequences of prolonged exposure to distressing material.

\section{Introduction}

Stress in police officers has been much researched over the last thirty years (Brown and Campbell, 1994; Brough et al, 2018) due to increased recognition that resulting physical and/or psychological impairment may contribute to impaired personal wellbeing and compromise work performance. Hesketh and Tehrani (2019) identified three at-risk police cohorts: (a) first responders, (b) those involved in major disasters, 
and (c) specialists who include police officers dealing with rape and sexual violence. Regarding the organisational context, Turnbull and Wass (2015) have outlined how austerity measures have made policing more complex and 'extreme', particularly regarding administrative responsibilities. Against this contemporary background of increasing demand, decreasing resources and greater performance scrutiny (Hesketh and Tehrani, 2019), challenging policing roles deserve fresh attention. This paper focuses on high-risk sexual violence investigations and their impact on female investigating officers as the interviewing of complainants is their likely province (Rich and Seffrin, 2014).. Despite the importance of the role of sexual offences investigation officers, McMillan (2015:623) observes that "the topic has received remarkably little attention in policing, criminal justice and criminological literature" meaning that theoretical understanding appears underdeveloped. The following sections set out why sexual offence investigations are much maligned in public view yet inherently stressful for those involved due to their psychological impact in terms of vicarious trauma (VT) and increased likelihood of post-traumatic stress. We argue that individual experiences and sense-making of officers remain under-researched.

The critical context of sexual offences investigations

The extent of rape complaints, media attention and scrutiny, the distress experienced by complainants and police investigators, and organisational responsibility for worker well-being frame the present study. The number of rapes reported to the police has increased threefold between 2017/18 and 2018/19 in the UK as the rate of successful convictions has declined by a similar proportion (HMICFRS, 2019). The UK's House of Commons Home Affairs Select Committee (2018) observed that the recorded number of child sex abuse cases had increased by $178 \%$ between 2007 and 2017. The police service's handling of such cases has been severely criticised for serious systemic shortcomings, lack of leadership and failure to take complainants seriously (Jay, 2014; Casey, 2016; Drew, 2016). The Metropolitan Police Service's (MPS) specialist units investigating sexual offences has had at least nine inquiries by the Independent Police Complaints Commission (BBC News 26th April 2013) who found missed investigative opportunities, complainants being encouraged to withdraw allegations to improve performance statistics and that female officers were unhappy with the working practices.

Working with sexual violence in the police

Documented stressors in police work include operational job demands, conflictual contact with the general public and structural aspects such as gendered and politicised occupational culture, team dysfunctions and poor managerial practices (Brown and Campbell, 1994). The masculine culture in the police has resulted in a potentially hostile climate for women officers and a belief that they are better suited to roles dealing with children and women (Brown et al, 1999; Jordan, 2002; Rich and Saffrin, 2014). McMillan (2015) implicates the police culture in the extent to which both police officers and supervisors undervalue the role of sexual offences investigators.

The investigation of sexual offences is a highly politicised and publicly scrutinised area of policing work. In the UK, a rape inspection report (HMICFRS, 2019) found that despite a sustained rise in rape allegations, there has been a dramatic fall in charges, prosecutions and convictions compared to previous years. For example, in 2019 fewer than 35\% of rape cases resulted in a charge, compared with 56\% in 2017. 
Whilst investigations into sexual offences have drawn criticism, limited attention has been paid to the impact on frontline officers (Angiolini, 2015). This review into the Metropolitan Police Service declared that some rape investigation officers suffered both burnout and compassion fatigue and the lack of occupational health support left them susceptible to vicarious trauma (VT). Moreover, the review reported that sickness was perceived as a weakness, compelling officers to hide it (Angiolini, 2015:49).

Working on sexual offences brings specific demands as officers must overcome natural human responses to distressing material and balance investigative objectivity with compassion for victims (Carney, 2004; Parkes et al, 2019a). Brown et al. (1999) reported for a sample of UK police officers that dealing with sexual assaults was amongst the top three factors leading to psychological distress, with female officers more adversely affected than male colleagues. Heavy caseloads also negatively affect police officers working on sexual offences (Wright et al, 2006).

Psychological impact

Craun and Bourke (2014) surveyed 600 members of an Internet Crimes against Children taskforce and reported the occurrence of secondary traumatic stress (STS) and that a higher STS score was a significant predictor of discomfort in expressing intimacy with the respondent's own children. Turgoose et al. (2017) also found that $26 \%$ of police officers investigating rapes had moderate, high or severe STS. Follette et al (1994) established that law enforcement professionals dealing with child sex abuse are at risk of experiencing traumatic symptoms. Specialised sexual assault nurses experience levels of cognitive disruption similar to those caused by personally experiencing a sexual violation, with $25 \%$ experiencing traumatic symptoms and clinical manifestations of VT (Raunick et al., 2015; Townsend \& Campbell, 2009).

STS, VT and compassion fatigue (Figley, 1995) derive from Post-Traumatic Stress Disorder (PTSD) symptoms experienced by those in helping professions exposed to the trauma of others, such as intrusive thoughts, hyperarousal and avoidance (Kanno and Giddings, 2017). STS is stress resulting from exposure to victim-presented trauma but different from burnout, which can be associated with working with difficult populations although not specific to working with traumatised clients or material (Kanno and Giddings, 2017). Burnout progresses gradually from cumulative wear and tear, excessive work-related demands and a lack of organisational support but does not have the trauma-related symptoms that define STS and VT (Jaffe et al, 2006; Trippany et al, 2004; Maslach and Leiter, 1997; Large, 2013). Typical symptoms of STS include depression and maladaptive coping behaviours (Basinka et al., 2014), which are particularly salient where there is a lack of equity in the relationship between professionals and those served by them - as is the case for police officers working with victims of sexual violence.

A qualitative study of officers investigating child sex abuse (Burns et al., 2008) found that constant exposure to suffering led to a breakdown in normal coping mechanisms, placing officers at higher risk of developing STS. Parkes et al. (2019a) found VT symptoms such as intrusive and unwanted thoughts and disruption to personal life in police staff who viewed online sexual offence material. In the first UK study examining STS in police officers investigating child sexual abuse, $34.6 \%$ had symptoms indicative of PTSD (Hurrell et al, 2018). In Turgoose et al (2017), officers 
working with adult victims experienced higher levels of STS and burnout than those working with children. Yet, a qualitative study of police officers working on child abuse in Australia found no evidence of distressing traumatic effects (Wright et al, 2006) and encouraged future research to explore whether these findings, at odds with previous studies on injury resulting from trauma exposure, might reflect an inability for officers to accurately identify and report on sources of stress. Whilst quantitative studies elucidate prevalence rates, qualitative approaches are warranted to investigate in depth the actual experiences of police officers involved in this area of work: this is the first qualitative study of its kind in the UK. This, we contend, is a critical context to understand officer experiences given the wider context of ongoing organisational change as well as public scrutiny.

VT refers to traumatisation observed in professionals who engage in cumulative, repeated work with individuals affected by trauma (Versola-Russo, 2006; Lerias and Byrne, 2003). VT has a cumulative manifestation compared to STS, which can occur as an immediate and sudden reaction to working with traumatised clients. VT seems to threaten the sense of safety, self-esteem, and intimacy (Parkes, et al, 2019a). Studies on helping professionals have articulated how corporeal expressions (e.g. feeling bodily dispersed, dislocated, and fragmented) play a role in professionals relating to the lived experiences of their patients (Lawler, 1997; Robinson, 2011). This sensory, empathetic exchange between professionals and others is referred to as 'corporeography' (Robinson, 2011). Cadwallader (2016) talks about the trauma of rape taking place in the wider context of 'wounding', where medical and judicial approaches attempt to silence and erase the memories of victims. The investigation of sexual offences is therefore a 'scene of wounding' as the corporeality of rape is categorised, displaced and reintegrated, leading to conflicted relationships with victims but also officers' own experience of 'wounding'.

\section{Interventions}

Turgoose et al (2017) reporting on police officers dealing with child sex abuse indicated that many of their participants commented on the benefits of being able to recognise and understand compassion fatigue and to 'give a name' to what they were experiencing. Others commented that they would appreciate further support from their employers at an organisational level to help them cope. Yet MacEachern et al (2011:334) observe that "there has been little impetus in the past for forces to acknowledge the effect of STS on its employees, specifically those tasked with investigating child abuse/child protection cases". They conclude that there are harmful effects of stress affecting not only officers' resilience but also resulting in negative impacts on operational effectiveness, with officers potentially falling short in their service provision. McMillan (2015) draws attention to the poor management of sexual offences investigating officers and the multiple demands being placed upon them. She concluded that there was a lack of shared understanding of the role at supervisory level. Brough et al (2016) suggest that effective management of occupational stress requires a thorough understanding of job specific stressors to meet the needs of police officers. They note interventions such as resilience training often neglects managerial and organisational shortcomings by placing the burden of maintaining wellbeing on individual officers.

Rationale for the present study 
There is an urgent need to better understand how female police officers are impacted by their duties in sexual offence units given their higher exposure to rape complainants and greater vulnerability to experiencing psychological distress (Turgoose and Maddox, 2017). Although all police work carries inherent risks this extreme policing work deserves particular attention because of its likely psychological impact due to working with distressing material and contentious cases yet in an impoverished support environment. A more nuanced approach to the personal impacts can provide not only enhanced theoretical understanding of the nature of such work, but also offer a better basis for recommendations to design and implement supportive interventions.

We adopted an idiographic approach, which commences with specific, individual cases to elucidate how individuals make sense of such experiences, professionally and personally. The following research questions guided our study:

How do policewomen working on sexual offences experience and make sense of their work?

How do they experience and make sense of the influence that their work roles have on their lives on the job and beyond?"

This study is original in its methodological choice as an Interpretative Phenomenological Analysis (IPA) focuses on the interaction between the disruption of cognitive schemas in VT and lived states from a deeply phenomenological perspective. Previous VT phenomenological research on other populations (e.g. Iliffe \& Steed, 2000 on domestic violence counsellors) highlighted discrepancies in findings generated by qualitative vs. quantitative studies on VT (e.g., Farrell \& Turpin, 2003) indicating that qualitative studies on VT are essential for advancing understanding in this area.

\section{Method}

Interpretative Phenomenological Analysis

IPA focuses on the individual lived experience through case-by-case analysis (Smith et al, 2009) and committed to understanding unique experiences involving heightened emotions and cognition/sense-making (Smith, 2019). IPA captures the way in which participants interpret their experiential world and encourages the researcher to be an active participant through empathetic interpretative engagements with the participant's account (Smith et al, 2009; Smith, 2008). One of us (AB) undertook the fieldwork and addressed this through reflective diaries and regular debriefing (with $\mathrm{AM}$ ) of her own sense-making and reactions to working with the interview material. JB's role was in framing the analysis and providing more detail of the policing background. We ensured reflective activity took place through collaborative reworking of the findings.

We analysed individual transcripts line-by-line following procedural guidelines by Smith et al. (2009) to safeguard the idiographic perspective by coding each transrcript as a distinct unit first, before progressing to the next one. The approach is outlined in the Appendix in more detail. We included interpretative comments on the scripts while remaining close to the participants words and experiences. Our engagement with the material had 'residual' effects (reported by Drozdzewski, 2015) which manifested as recurrent imagery and emotive reactions during the analytical process. 
Parkes et al (2019a) found instances of 'indelible' images recalled by their respondents when dealing with graphic sexual materials. We experienced this with the 'red sandals' image (given later in the text) of the paper's title as having particular powerful resonance. In turn, this served our reflexivity to be more sensitive to the participants accounts (Campbell, 2013). Our attending to these residual 'echoes' (Goldspink and Engward, 2019) resulting from the visceral and physical imagery continued to resonate over a period of some months which prompted a deeper engagement with the mental and physical experiences of our participants.

We constructed a table of superordinate themes and sub-themes for each participant (Smith et al. 2009) and summarised patterns and divergences across cases in a master table of themes using detailed examples from particular cases.

Participants

We sent an open invitation to take part in the research to sexual offences teams, which resulted in fifteen female police officers ( 9 detectives and 6 non-detective officers) who had current or recent (i.e. less than a year ago) experience of working in sexual offence units in a large Metropolitan Police Force in England being recruited.

Following initial contact, all interviewees were emailed an information sheet and informed consent forms to sign to take part in the study. The age range was 24 to 51 years (average 38). Their involvement in rape investigations ranged from 8 months to 29 years (average 5 years). Contextualised demographic information is given in Table 1. (We limited this to avoid any possible identification of our respondents)

Table 1: Participants' demographics

\begin{tabular}{|c|c|c|c|c|}
\hline Pseudonym & Age & $\begin{array}{l}\text { Years working in } \\
\text { rape } \\
\text { investigations }\end{array}$ & $\begin{array}{l}\text { Rank/Posi } \\
\text { tion }\end{array}$ & Role \\
\hline D1 & 37 & 10 years & $\mathrm{PC}^{*}$ & Victim support \\
\hline D2 & 43 & 13 years & $\mathrm{DS}^{* *}$ & Detective \\
\hline D3 & 24 & 8 months & $\mathrm{PC}$ & Victim support \\
\hline D4 & 43 & 9 years & DC & Detective \\
\hline D5 & 44 & 10 years & $\mathrm{PC}$ & Victim support \\
\hline D6 & 46 & 7 years & DC & Detective \\
\hline D7 & 49 & 29 years & DC & Detective \\
\hline D8 & 42 & 4 years & $\mathrm{PC}$ & Victim support \\
\hline D9 & 31 & 2 years & PC & Victim support \\
\hline D10 & 43 & 15 months & DC & Detective \\
\hline D11 & 26 & 1 year & DC & Detective \\
\hline D12 & 32 & 7 months & DC & Detective \\
\hline D13 & 31 & 8 months & DC & Detective \\
\hline D14 & 51 & 6 years & $\mathrm{PC}$ & Victim support \\
\hline D15 & 33 & 8 years & DC & Detective \\
\hline
\end{tabular}


$* \mathrm{PC}=$ Police Constable, $* * \mathrm{DS}=$ Detective Sergeant,$* * * \mathrm{DC}=$ Detective Constable1 Data Collection

We commenced the in-depth semi-structured schedule with rapport building icebreakers (general questions on career in the police) to frame questions about involvement in rape investigation including sample questions such as 'Can you tell me more about how you experience your work in this context?', 'How do you feel when you talk about it?', 'On a day-to-day basis, how do you deal with the nature of your work?' or 'How does your work affect your everyday life?'. Interviews lasted between 35 and 110 minutes, audio-recorded for accurate transcription. The first researcher transcribed each interview using basic transcription style (i.e. verbatim transcription with basic punctuation) to protect the participants' anonymity and the sensitivity of data but also limit the impact of traumatic content on transcriptionists (Dickson-Swift et al, 2008).

Ethical Considerations

The study received ethical approval from the host research institution and permission to access participants from the participating police service. The first researcher $(\mathrm{AB})$ collected all data and positioned herself as a researcher external to the organisation drawing on her policing knowledge (being involved in leadership training) to build rapport. We took several additional steps alongside standard ethical procedures to minimise risk of harm to participants; for instance we asked no direct questions about specific rape incidents, informed participants about support and counselling facilities and undertook detailed debriefings at the end of each interview.

\section{Findings}

We outline the findings according to superordinate and constituent themes and illustrated with particularly pertinent quotations from individual participants in Table 2 .

Table 2: Superordinate themes and constituent themes

\begin{tabular}{|c|c|}
\hline Superordinate themes & Constituent themes \\
\hline Relating to victims & Intimacy \\
\hline 'You're connected, there's no breaking & Weariness \\
\hline that connection, and when they want & Responsibility and fear \\
\hline $\begin{array}{l}\text { you or need you, you can't shut the door } \\
\text { on them' (D1, 254) }\end{array}$ & Disillusionment \\
\hline The ailing self & Symptoms \\
\hline 'I had been ill for a long time, my body & Sexuality \\
\hline had been telling me' (D2, 271) & Parenthood \\
\hline Coping with the job & Retreat \\
\hline 'It's like I've been branded with some & Hardening up \\
\hline bloody iron and no matter how much & Shutting down \\
\hline
\end{tabular}

\footnotetext{
${ }^{1}$ In the context of sexual offences, a Detective Constable (DC) is the officer responsible for the investigation, while a Police Constable (PC) deals with victim care and support. A Detective Sergeant (DS) is a rank above DC and has supervisory responsibilities for several DCs. DS is often the investigative lead for complex or sensitive cases (e.g. linked series offending, sensitive or high-profile victim or suspect).
} 
you try and hide they'll find you' (D1,

1260)

\section{Relating to victims}

This theme captured increasing intensity of the powerful connections the officers had with complainants including contradictory emotions of intimacy, weariness, disillusionment, fear and responsibility.

\subsection{Intimacy}

Officers developed intimacy through the sharing of details of sexual experiences or personal anatomy otherwise only known to the victims' sexual partners. Sometimes the victims reminded them of other people close to them, such as a younger sibling or family member, or of previous personal experiences. In D1's account, there was a palpable undertone of unconditional love with language invoking caring and the notion of an unbreakable bond with each victim.

I remember all my girls, and my boys, and the boys and girls I've worked for and cared for and looked after. I love them all very much in my own little way, because although you have a professional boundary, when you're sharing an intimate experience - especially sexual experiences - and you ask people about their body parts and what happened to them...And some people have medical conditions, they have a bad smell or an injury down there, or something they're not very proud of because they may have excessive hair, or something happens to them when they have sexual intercourse with their partners, they tell you this in the interview, they tell you in confidence so when they've shared that with you, nobody else probably knows apart from someone that's been to that part of their body or laid with them. You're connected, there's no breaking that connection, and when they want you or need you, you can't shut the door on them (D1, 244-254)

\subsection{Weariness}

Yet such intimacy was intertwined with feelings of weariness where personal and professional boundaries were weakened as 'needy' victims required constant care and attention during prolonged contact. D1 described her sense of emptiness after completing interviews with victims:

...by the time you come out of that interview and it's all finished it's such a relief it's like being unplugged and you feel like you want to collapse into a bag, it's like you're a skeleton with no bones by the time you finish because you're completely down and you just need to go and rest but of course there is no rest (D1, 352-355)

The strength of the images captured the relentlessness of sacrificing vitality and life energy to transfer reserves to the victim, leaving the officers with no structure and residual feelings of lifelessness, hollowness and vacancy. The interaction with the victim resulted in her collapsing into a bag, which evoked the image of a body-bag and her figurative death. D9 also described the experience of listening to victims as a process of sucking life out of her as the slow destruction of her life-sustaining force became noticeable to others around them: 
I feel that it's zapped every bit of energy from me, mentally and physically because it's a lot of stress and it's a lot of tension (124-126). I've got friends and even my boyfriend said 'you're not the person that you were, you were really bubbly when you first started there and it's just zapped the life out of you' (178-180)

\subsection{Responsibility}

Participants repeatedly spoke about their experience of feeling overwhelmed with responsibility towards victims and fear of further harm as a constant burden. D6 described the harrowing realisation that she had made a mistake in her investigation of a brutal rape.

I went into the evidence box and admitted I made a mistake but I came out of it absolutely hysterical, thinking 'oh my God, this whole case just rests on me now and I've completely messed it up!' ...I remember thinking to myself: if this guy gets off with it I'll never get this out of my head and I'm going to have to bang my head against a brick wall to get this stuff out of my head because I can't allow this to happen (D6, 180-186).

D6's torment and inner battle affected her whole person embodied in her visceral account of wanting to hurt herself, describing the pain associated with the consequences of her actions which dominated her thoughts.

\subsection{Disillusionment}

Work was also experienced as grinding and frustrating due to the perception of victims' dishonesty. D6 recounted the enthusiasm of her first few years at work but over time, the belief in false allegations increased straining her ability to work on 'real' cases resulting in a sense of ingratitude and even dislike of victims, who did not appear to appreciate the demands placed on officers.

It just comes down to the fact that victims don't tell the truth to be honest with you, and you're dealing with a crime that you know in the nicest possible way is a load of nonsense and I wouldn't say that, this is my example, if you had ten jobs you'd probably have two which were top quality jobs, and two where they had lied, and the rest in the middle would be a mixture of half-truths, truths, he-said-she-said kind of stuff and that starts to grind you down, it truly does (D6, 82-87).

Her sense making implied that establishing the truth is essential to an investigator and that vague reports tarnished the very meaning of rape as a crime, leading to wider disillusionment with the job.

2. The ailing self

All participants charted a vivid experience of gradual mental and physical decline.

\subsection{Symptoms}

Becoming unwell took the form of a gradual deterioration arising from the experience of physical and emotional harm. D2 talked about struggling with a constant sore throat, which she interpreted as compassion fatigue signalling her gradual decline and self-neglect leading to a disembodied self. 
I was exhausted, mentally and physically exhausted (...) I knew I had been ill for a long time, my body had been telling me, I used to be covered in psoriasis, I've got IBS, I've got stomach ulcers. All from stress, I go to the doctor's and they go 'what do you expect?', covered in psoriasis, on my hair, my hair used to fall out so I had physical signs of stress (D2, 270-274)

Participants described vividly the experience of the slow erosion of self and irreparable damage in contrast to their previous selves - full of life, vitality, and happiness:

Everyone's broken, all of my friends that were happy bubbly - me included, all a little washed out, we've got bags under our eyes, all wearing the same clothes from yesterday, they haven't ironed their shirts. We are absolutely pooped (D1, 445-448)

Most participants described living through intense anxiety attacks recounted as feeling finished, broken and paralysed with fear, as in D3's experience:

I was depressed I would say, I was very very irritable, I was angry, I was very anxious. I think I almost got a little paranoid (D3, 98-99). I have never in my life had a panic attack before and I haven't had once since... it was weird tingling down my legs and arms, really intense to the point where my hands clenched up into fists and I couldn't move my hands (D3, 103-08)

All participants described sleep disturbances as frequent occurrences often reliving details from individual cases who came to haunt them in nightmare-like scenarios:

I woke up and I had my eyes open, and I had my duvet over my head and I looked out and I could see baby's legs and two red sandals and little socks, I didn't see his face but I could see he was sitting on the side and I just saw him doing that, and of course he wasn't there. It was like a baby sitting next to me, white socks, red shiny buckle up shoes, and it was like he was waiting for me to wake up just sitting there waiting, and I threw back the covers and he wasn't there (D2, 172-178).

The detail of the shoes made the nightmare vivid and still present or easily recalled. For D15, nightmares revealed a sense of personal vulnerability and extreme distress, of being overpowered and subjected to pain where she took on the experience of her victim without being able to escape:

When I'm at peak stress I have nightmares where, it's never somebody else, it's me being raped...can be at knife point, it can be gang, it can be me running and being caught and then held and raped (D15, 633-635)

\subsection{Sexuality}

Sexuality with partners was presented as disturbed, impoverished and violated as the emotionally charged work encroaches intimacy occasionally going as far as images of intertwined abuse. This in turn affected self-disclosure and closeness with their partners. Sex became associated with violence, which cumulatively effected affected their relationships with men through a loss of trust: 
I think I am put off of men; it puts you off your sex life. It doesn't make you trust anybody, and that's because I have been doing it over a period (D4, 301-302).

\subsection{Parenting}

The officers' work experiences also affect relationships with their children as participants became wary and overprotective mothers. D1 described her constant fear that her child might, through uncontrollable circumstances, become either a victim or an offender. Such devastation was portrayed as an urge to physically put up barriers, move country and leave the job mixed with awareness such worries have elements of absurdity:

And this is what I'm thinking about for my kid, so you think about barricading the doors, moving country, going to another island, giving up your job. How can I keep him safe from this? And these thoughts cross your mind all the time to the point where I am looking at home schooling him, I am looking to completely change my career (D1, 797-801)

The impact on her as a mother was expressed by D7 as intolerance, constant suspiciousness and anger with any men that would 'leer' at her teenage daughter. There was also a sense of hyper-vigilance born out of the work.

I remember one particular [party] and all the other parents just dropped their kids off there. Oh no, not me: I would sit there in the car park because I didn't know who the parents were, and in my mind, I'm thinking the worst. You know, there are all these things from work, all start coming into your head and you're thinking what's going to happen here? (D7, 272-279)

This theme encompassed feelings of loss, emptiness, as well as being consumed, trapped and incarcerated where survival at work was expressed as a need to become a desensitised automaton.

3. Coping with the job

There was a temporal element to individuals' sense making as a vivid indication of how they sought to cope, particularly for the officers involved in rape investigations for sustained periods of time.

\subsection{Retreat}

Participants talked about feeling drowned and consumed by the volume of work, which invaded their private lives and interrupted important family events. Coping involved missing out on family occasions.

I remember...I had a BBQ and all the family were over and it's because I got in at three/four in the morning...I wasn't there until the end of the day by the time I had got up and had a shower... (D2, 291-301)

Her regret was expressed as an irretrievable loss of a significant and precious part of her personal life. D1 described this loss as being 'branded with iron', which implies enslavement and a sense of permanent ownership by the organisation. 
It's not like you can just let your driving license expire or your first aid certificate run out. It's like I've been branded with some bloody iron and no matter how much you try and hide they'll find you, they're going to deploy you, you're going to be done, back out there again and once you're back in the mix it's like a toilet being flushed you're going round so fast nobody can help you, everybody is trying to save themselves (D1, 1259-1264).

The metaphors used here were powerful: the person is equated to excrement being flushed down the toilet, surrounded by others in a similarly distressed state, trying to save themselves or regain a sense of dignity and selfhood. There is a feeling of 'being treated like shit' (D5, 347), of ungratefulness and lack of organisational care, expressed by all as doing something that is not recognised, feeling worthless, 'the lowest of lows' (D5, 362) or doing a job where there is 'no gratitude' $(\mathrm{D} 9,542)$. Given these experiences, the solitude of the role was compounded by feeling depersonalised and devalued by the organisation.

\subsection{Hardening up}

Overall, work led to a loss of vitality, vivacity and of inner strength. The only way to survive was described as a need to 'harden-up', symbolically contrasted to a breaking and damaged self. D3 talked about her resistance to becoming desensitised: 'you're not hard enough, you'll harden up and I didn't want to harden up really' (220-221). For others, the inability to regain structural strength and desensitise was experienced as a feeling of raw vulnerability and powerlessness. For D2, excessive exhaustion brought back images of abandonment and exposure to previous violence: when I get very tired and exhausted, that's when I felt vulnerable, that's when I felt vulnerable as a child when I was getting beaten and hit so can you see the link? Vulnerability, tired, no one looking after me, that's me as a child sitting watching my mum get beaten up every day and just sat at the top of the stairs not being able to do anything. That's the link (D2, 301-305).

The work habitually led to a state of despondence, vulnerability, feeling out of control, unsafe and abandoned. Participants made sense of this through a cognitive process of dehumanisation and desensitisation to become a 'military robot' (D1, 1278) without feelings and elements of one's human self. In D6's words one needs to be hard-faced to survive: 'some people can take that and I could but as time went on I just had nothing more to give really, it was just eating me up, and every part of me was slowly eroded' (198-200).

\subsection{Shutting down}

D2 described how her own body was ailing and shutting down.

I was getting the handover, and she was looking at me and I was going, you know that echo, it was like someone was doing that in my ears, and I was like 'God, I can't hear what you are saying!' and my body was literally just shutting down (286-287).

She emphasised throughout her interview that she was normally a strong person yet anxiety and illness came to the surface: her body was trying to expel the damage caused by traumatic secondary experiences in an attempt to repair itself. 
At the same time, participants also spoke about the despair of being trapped in an institutional machinery where they were robots or 'just a number' (D9, 497). D6 described it as imprisonment:

you're not the prisoner, you haven't done anything wrong but you're being treated like you have because in my head the only way I could get out of there was to either resign or I was getting taken out in a box (D6, 484-487)

The image of a coffin symbolically captured self-annihilation and loss of life, accentuating her experience of being punished, treated badly, and her reduced sense of agency and freedom. In a few extreme cases this was expressed in the form of suicidal ideation or the obliteration of self:

I am still not better but I was in a state... I was suicidal, I wanted to kill myself, I was planning my death. (D2, 413-415)... The only reason why I didn't is because I didn't think anyone would find me and I didn't want to be left dead in my house for months until someone noticed I wasn't at work or whatever (D2, 417-420).

\section{Discussion}

Our deeply interpretative stance on female police officers' lived experience of officers working on sexual abuse cases revealed how individual wellbeing was being eroded. Respondents spoke about their feelings towards victims, of shutting down, living through panic attacks, night terrors, disturbed sexual intimacy and hypervigilant parenthood. Their words conveyed vivid, visceral images, tangible emotions and cognitions of ailment, disintegration, alienation, annihilation and enslavement. These encompass a sense of being mentally and physically wounded and marred for life. "Little red sandals" cannot be forgotten; neither can the spectre of turning into a "skeleton with no bones" as a hollow, ghost-like shell. Officers conveyed their sense of entrapment as there was a paradox between wanting to be a good investigating officer yet finding it hard to separate the self from the 'deserving' victim or distancing themselves from 'ungrateful' victims.

The violent bodily descriptions in our participants' accounts stand out as a way of relating to the corporeality of rape but also of processing their own expressions of trauma. The richness of perceptual detail and sensory words in their accounts aligns with findings that PTSD is associated with lower levels of cognitive processing (i.e. 'hot' rather than 'cool' cognitions from an IPA perspective) but produces sensory and movement visualisations that are different from ordinary memories verbalised as processed emotional states such as fear or guilt (Hellawell and Brewin, 2004; Jelinek et al., 2010). The participants' sense making indicates a certain level of 'self-hate' enmeshed with the victims and their experiences of sexual violence which in turn coloured the participants accounts of relationships with children and partners.

The vivid experiences relayed here converge with those reported in other studies on clinicians working on sexual victimisation (Tabor, 2011; Raunick et al, 2015). All participants in this study reported symptoms associated with VT such as depression, anxiety, suicide ideation, burnout, intrusive imagery and altered beliefs and cognitions, disrupted intimacy, and a perceived loss of trust and control (Jaffe et al, 2006; Large, 2013; Parkes et al, 2019a). VT can result in avoidance, dissociation, and 
a reduction in victim care (Raunick et al, 2015; Lerias and Byrne, 2003). This is illustrated in the weariness, disillusionment and fear that participants experienced when relating to victims. VT can manifest as over identification with victims (Brady et al, 1999) but also as dissociation. The latter can be seen in the imperative of becoming desensitised or of 'hardening-up', which some participants perceived as the only coping option for functioning in their roles. This dissociation often occurs as a result of excessive perspective taking, supported by previous research on the desensitisation bias and empathetic gap in own reactions linked to repetitive exposure to others' experiences (e.g. Campbell et al, 2014) which is also evident in the officer accounts detailed here. Yet this hardening up was in contrast, and occasionally a lived paradox, compared to the vivid emotions of self-loathing and loss of sense of self participants turned into 'shit' or nothings as 'skeletons without bones'. These emotional aspects which also had vivid physical manifestations particularly in terms of disrupted sleep and dreaming have not yet been addressed in such detail in the literature.

Intimacy with partners is often disrupted in VT through intrusive imagery from the victims' experiences of trauma (Trippany et al, 2004). VanDeusen (2006) found that disrupted cognitions about intimacy with others were significantly higher in those working on sexual abuse compared to other mental health professionals. This study lends support to these findings, as intrusive imagery and distorted intimacy are also an experiential feature for the present participants. Symptoms of VT also include hypervigilance and a heightened perception of threat, feelings of helplessness and anxiety, impairment in personal functioning in other areas of life, recurrent distressing dreams and difficulties staying or falling asleep (Lerias and Byrne, 2003; Cunningham, 2003). In similar terms, participants described their experiences of becoming overprotective and hypervigilant in their parental roles, the depletion of their family life, and their struggles with anxiety attacks and night terrors. VT can affect cognitive schemas and world beliefs (Brady et al, 1999), which is well illustrated in D1's declaration that she had considered home-schooling and moving countries as strategies for protecting her own child from sexual abuse.

Participants reported feeling trapped, overwhelmed, fatigued, hopeless and helpless at work, aligned to findings of VT and STS in other professionals but also to burnout symptoms (e.g. Raunick et al, 2015; Jaffe et al, 2006). For example, the participants' loss of self converges with the depersonalisation experienced as a result of burnout (Basinka et al, 2014; Maslach and Leiter, 1997). It may be that burnout symptoms, such as exposure to work overload, feeling a loss of control and a lack of reward and fairness (Maslach and Leiter, 1997) are intertwined with VT for some participants. An organisational culture where self-care is not prioritised and valued, or where individuals have diminished control over their work can exacerbate the risk of experiencing STS and VT (Large, 2013; Kulkarni et al, 2013). Burnout, which is often associated with feeling emotionally exhausted and overworked, can increase the officers' vulnerability to VT (Jaffe et al, 2006; Liberman et al, 2002). The symptoms of burnout are more apparent in the last theme of our study regarding the legacy of the job, where participants described feeling drowned, exhausted and consumed by the volume of work. We also noted a somewhat drastic and intense form of spillover - the concept from the work-life balance literature where what happens in one domain triggers mirror effects. Here, traumatic investigative experiences were relived in partnerships, relationships with children but also perpetuated through the unconscious 
manifesting in nightmares, leaving participants trapped, imprisoned, and undervalued without escape. The participants' experiences denote lack of self-care and acute loss of control and sense of reward, symptomatic of burnout

In addition to the core findings reported above, all respondents referred to problematic aspects of their current organisational environment including bullying, working in teams that constantly change, and a lack of peer support. Several officers noted lack of care from managers/supervisors; lack of leadership and not feeling heard and appreciated (officers with main responsibility for supporting victims often described themselves as 'the lowest of lows'/'lowest in the pecking order'). Continuous budget cuts, long hours, high caseload (e.g. 22 to 31 cases) and poor work-life balance were believed by all to be detrimental to their wellbeing.

Similar to Wright, Powell and Ridge (2006) there was a perception that officers get blamed and ostracised if unwell, over half said that reporting mental ill health would lead to the ending of their career and nearly all spoke about the stigma attached to mental illness (e.g. being branded as incompetent or over-emotional). Some spoke of taking annual leave to hide mental illness but as this increases workloads for others, it impacts team relations and makes it more difficult to return to duty. Most felt support from occupational health services was inadequate.

Limitations and directions for future research

Given our focus on individual sense-making of professional experiences and the voluntary aspect of providing informed consent, it was beyond the scope of our study to pre-screen participants for the effects prolonged exposure to trauma, or indeed previous experience of any trauma, might have had on them. Whilst engaging with the participant experiences, it appeared tenable that some participants had had relevant experiences. As we conducted research interviews, and not clinical interviews, we refrained from probing if participants did not disclose voluntarily. That said, it is also clear from the demographic data that some participants had spent an extraordinarily long time working with distressing material. Future research would do well to investigate the effects of repeat and prolonged exposure, particularly where participants have a relevant history. Both aspects would appear to require particularly sensitive and appropriate support mechanisms, and also underline that VT may not be solely an individual phenomenon but shaped through a historical and organisational context.

Theoretical and practice implications

Our key theoretical contribution is to assess the content of certain policing roles exemplifying 'extreme work' and pay attention to the material and context officers work with, rather than frame extreme work mainly in terms of work overload and intensification. Our data vividly illustrates the profound and lasting impact on officers involved. Our second contribution is a refined understanding of VT in this context which, as our data documents, is a complex construct at the interplay of personal experience particularly in terms of strong emotions and vivid physical manifestations, but catalysed by a lack of organisational support and an unresponsive culture. Therefore, we caution against positioning VT as a primarily individual experience. We draw analogies to burnout, which the World Health Organisation conceptualises as an organisational phenomenon, rather than a medical condition (WHO, 2019). 
A number of studies note the lack of effective support for officers investigating sexual offences (Angiolini, 2015; McMillan, 2015) and call for improvements. The current research confirms and emphasises these findings and highlights the need to increase education for both police officers working on sexual victimisation and their supervisors of the consequences of VT and STS. Investigative practitioners working on sexual violence need to be aware of the vicarious effects of their work, which could be advanced through several practical measures. First, assessments of individual differences indicating vulnerability to STS and VT can be further refined to incorporate recent research findings. Second, police organisations should offer regular and structured opportunities for peer supervision, support and debriefing. Third, training on traumatology and on how to recognise warning signs of VT in both the individual officer and their supervisors. Fourth, opportunities created for clinical supervision or access to trauma counselling services. Clinical supervision encourages self-monitoring and reflexivity and is established in other therapeutic settings with evidenced positive outcomes for practitioners and clients (e.g. Wheeler and Richards, 2007). Wellbeing strategies need to incorporate self-care activities specifically related to VT risks and effects. Finally, organisations should also review tenure, training and supervision procedures to reduce caseloads and offer shorter/fixed role tenure while promoting opportunities to leave roles or work part-time. Dedicating more resources to this area of work is expected to have a positive impact on victim care and on current concerns about the low number of reported rapes being prosecuted.

Also, as the Drew report recommended, encouraging supervisors to be more professionally curious rather than obsessing over performance indicators would be helpful (Drew, 2016). Moreover, improving organisational health support would be valuable and could take the form of encouraging confidential reporting of stress and actively supporting officers to take leave if needed without suffering professional recriminations (Hesketh et al, 2014).

In response to the advice from Brough et al. (2015) to fully understand the specific nature of stressors, this study identifies the enmeshed and conflicted relationship between victims and officers experiencing VT, which results in responses torn between extreme caring, over-identification and aversion to victims. In other words, vulnerability to VT translates as an unresolved and decentred vacillation between selfconsuming intimacy with victims, and a self-restoring strategy of emotional distancing and empathetic numbing. All of these are marked by vivid visceral experiences. We suggest that further research to explore this conflict would assist in targeting debriefing and support.

We offer a cautionary note about debriefing. There is a lack of definitive evidence to support the efficacy of Mitchell's (1983) Critical Incident Stress Debriefing as an intervention to mitigate police reactions to trauma exposure. Rich and Briner (2012) found that some individuals actually suffered adversely from re-living a traumatic incident in such a formal and structured way. Parkes et al. (2019b) suggest that trauma exposure experienced by police staff working with sexual violence is persistent and pervasive rather than a discrete trauma event. They advocate a range of methods for facilitating exploration of the effects from this type of police work including keeping a reflective diary, regular peer support sessions, and clinical supervision, typical in other helping professions. Further research could assess the effectiveness and impact 
of such supervision on vicarious effects ensuring that the relevant professionals are conversant with a policing context. The job demand characteristics of a police officer (in terms of the unscheduled timings of offences) means that there should be flexibility in the timing of support interventions.

\section{Conclusion}

The paper contributes to a nascent literature on detailed examinations of specific sources of stress in 'extreme' police work and provides a detailed understanding of individual impact. Framing participants' responses with the concept of corporeography showed they become on the one hand enmeshed with their victims and investigations, and on the other hand disillusioned and 'hardened up'. Our research reveals deep and common experiential themes and raises important opportunities for further research on operationalising and measuring VT (Kadambi and Ennis, 2004) and its subjective nature (Large, 2013). The constructs unveiled here offer the opportunity to further refine and extend current VT measures and point to a need to assess police officers' wellbeing more clinically in the context of supportive supervision from superiors, peers and professionals. We hope that a focus on understanding and improving organisational and individual opportunities for self-care practices and in particular monitoring these during long-term exposure to secondary trauma would benefit the officers involved. We call for VT to be recognised as an organisational phenomenon rather than purely individual experience. Such effects are cumulative over time hence the findings should inform future, more targeted support activities given the profound psychological consequences of prolonged exposure to extreme and distressing material. 


\section{References}

Abdollahi, M. K. (2002). Understanding police stress research. Journal of Forensic Psychology Practice, 2(2), 1-24.

Angiolini, E. (2015). Report of the independent review into the investigation and prosecution of rape in London. Metropolitan Police Service.

Brady, J.L., Guy, J.D., Poelstra, P.L., and Brokaw, B.F. (1999). Vicarious traumatization, spirituality, and the treatment of sexual abuse survivors: a national survey of women psychotherapists. Professional Psychology: Research and Practice, 30 (4), 386-393.

Brown, J. M., and Campbell, E. A. (1994). Stress and policing: Sources and strategies. John Wiley and Sons.

Brown, J, Fielding, J., and Grover, J. (1999). Distinguishing traumatic, vicarious and routine operational stressor exposure and attendant adverse consequences in a sample of police officers. Work and Stress, 13, 312-325.

Brough, P., Brown, J. M., and Biggs, A. (2015). Improving criminal justice workplaces: translating theory and research into evidence-based practice. Abingdon: Routledge.

Brough, P., Drummond, S., and Biggs, A. (2018). Job support, coping, and control: Assessment of simultaneous impacts within the occupational stress process. Journal of Occupational Health Psychology, 23(2), 188-197

Burns, C. M., Morley, J., Bradshaw, R., and Domene, J. (2008). The emotional impact on and coping strategies employed by police teams investigating internet child exploitation. Traumatology, 14(2), 20-31.

Cadwallader, J.R. (2016), Forgetting rape: trauma, pharmaceuticals and embodied (in)justice. Australian Feminist Studies, 31, 88, 125-138.

Campbell, R. (2013). Emotionally involved: The impact of researching rape. Routledge.

Campbell, T., Van Boven, L., O’Brien, E., and Schwarz, N. (2014). Too much experience: a desensitization bias in emotional perspective taking. Journal of Personality and Social Psychology (106), 2, 272-285.

Carney, T.P. (2004). Practical Investigation of Sex Crimes: A Strategic and Operational Approach. Boca Raton, FL: CLC Press.

Casey, L. (2015). Report of inspection of Rotherham metropolitan borough council https://assets.publishing.service.gov.uk/government/uploads/system/uploads/attachme nt data/file/401125/46966 Report of Inspection of Rotherham WEB.pdf 
Craun, S.W., and Bourke, M.L. (2014). The use of humor to cope with secondary traumatic stress. Journal of Child Sexual Abuse, 23 (7), 840-852.

Cunningham, M. (2003). Impact of trauma work on social work clinicians: empirical findings. Social Work (48), 4, 451-459.

Dickson-Swift, V., James, E. L., Kippne, S., and Liamputtong, P. (2008). Risk to researchers in qualitative research on sensitive topics: issues and strategies, Qualitative Health Research, 18 (1), 133-144.

Drew, J. (2016). An independent review of South Yorkshire Police's handling of child sexual exploitation $1997-2016$ http://www.drewreview.uk/wp-content/uploads/2016/03/SYP030-Final-report.pdf

Drozdzewski, D. (2015). Retrospective reflexivity: the residual and subliminal repercussions of researching war, Emotion, Space and Society, 17, 30-36.

Figley, C. R. (1995). Compassion fatigue as secondary traumatic stress disorder: An overview. In C. R. Figley (Ed.), Compassion fatigue: Coping with secondary traumatic stress disorder in those who treat the traumatized (pp. 1-20). New York, NY: Brunner-Routledge.

Follette, V.M., Polusny, M.M., \& Milbeck, K. (1994). Mental-health and lawenforcement professionals - trauma history, psychological symptoms, and impact of providing services to child sexual abuse survivors. Professional Psychology-Research and Practice, 25(3), 275-282.

Goldspink, S., and Engward, H. (2019). Booming clangs and whispering ghosts: Attending to the reflective echoes in IPA research. Qualitative Research in Psychology, 16 (2), 291-304.

Hellawell, S.J., and C.R. Brewin (2004). A comparison of flashbacks and ordinary autobiographical memories of trauma: content and language. Behaviour Research and Therapy, 42 (1), 1-12.

Hesketh, I., Cooper, C. L., \& Ivy, J. (2014). Leaveism and public sector reform: will the practice continue? Journal of Organizational Effectiveness: People and Performance. 1(2):205-212.

Hesketh, I., and Tehrani, N. (2019). Psychological trauma risk management in the UK police service. Policing: A Journal of Policy and Practice, 13(4), 531-535.

HMICFRS (2019). National Child Protection Post-Inspection Review Metropolitan Police Service 8-19 October 2018 March 2019

https://www.justiceinspectorates.gov.uk/hmicfrs/wp-content/uploads/metropolitannational-child-protection-post-inspection-review.pdf

House of Commons Home Affairs Committee (2018) Policing for the future Tenth Report of Session 2017-19 
Hurrell A.-K., Draycott S., \& Andrews L. (2018). Secondary traumatic stress in police officers investigating childhood sexual abuse. Policing: An International Journal of Police Strategies \& Management,

Jaffe, P.G., Crooks, C.V., Dunford-Jackson, B.L., and Town, M. (2006). Vicarious trauma in judges: the personal challenge of dispensing justice. The Judges' Journal, 45 (4), 12-18.

Jay, A. (2014) Independent Inquiry into Child Sexual Exploitation in Rotherham (1997 - 2013)

https://www.rotherham.gov.uk/downloads/file/1407/independent inquiry cse in roth erham

Jelinek, L., Stockbauer, C, Randjbar, S., Kellner, M., Ehring, T., and S. Moritz (2010). Characteristics and organisation of the worst moment of trauma memories in posttraumatic stress disorder. Behaviour Research and Therapy, 48 (7), 680-685.

Jordan, J. (2002). Will any woman do? Police, gender and rape victims, Policing: An International Journal of Police Strategies and Management, 25(2), 319-344.

Kadambi, M.A., and Ennis, L. (2004). Reconsidering vicarious trauma: A review of the literature and its limitations. Journal of Trauma Practice, 3 (2), 1-21.

Kanno, H., and Giddings, M.M. (2017). Hidden trauma victims: Understanding and preventing traumatic stress in mental health professionals. Social Work in Mental Health, 15 (3), 331-353.

Kulkarni, S., Bell, H., Hartman, J.L, and Herman-Smith, R.L. (2013). Exploring individual and organizational factors contributing to compassion satisfaction, secondary traumatic stress, and burnout in domestic violence service providers. Journal of the Society for Social Work and Research (4), 2, 114-130.

Large, S. (2013). Vicarious trauma: A covert threat?. Clinical Psychology Forum, $251,44-49$.

Lerias, D., and Byrne, M.K. (2003). Vicarious traumatization: symptoms and predictors, Stress and Health, 19, 129-138.

Liberman, A.M., Best, S.R., Metzler, T.J., Fagan, J.A., Weiss, D.S., and Marmar, C.R. (2002). Routine occupational stress and psychological distress in police. Policing: An International Journal of Police Strategies and Management, 25(2), 421439.

MacEachern, A. D., Jindal-Snape, D., \& Jackson, S. (2011). Child abuse investigation: police officers and secondary traumatic stress. International journal of occupational safety and ergonomics. 17(4), 329-339. 
Maslach, M.A. and Leiter, M.P. (1997). The Truth About Burnout: How Organizations Cause Personal Stress and What to Do About It, New York: JosseyBass.

McMillan, L. (2015) The role of the specially trained officer in rape and sexual offence cases. Policing and Society, 25:6, 622-640,

Mitchell, J. T. (1983). When disaster strikes: The critical incident stress debriefing process. In Journal of emergency medical services. January: 36-39.

Parkes, R., Graham-Kevan, N., and Bryce, J. (2019a). You don't see the world through the same eyes any more: The impact of sexual offending work on police staff. The Police Journal,92(4), 316-338.

Parkes, R., Graham-Kevan, N., and Bryce, J. (2019b). 'I put my “police head” on': Coping strategies for working with sexual offending material. The Police Journal, 92(3), 237-263.

Raunick, C.B., Lindell, D.F., Morris, D.L., \& Backman, T. (2015). Vicarious trauma among sexual assault nurse examiners. Journal of Forensic Nursing, 11 (3), 123-128.

Rich, K., and Seffrin, P. (2014). Birds of a feather or fish out of water? Policewomen taking rape reports. Feminist criminology,9(2), 137-159.

Robinson, C. (2011). Beside One's Self: Homelessness Felt and Lived. Syracuse University Press: New York.

Smith, J. (ed.) (200). Qualitative Psychology. A Practical Guide to Research Methods. London: Sage.

Smith, J. (2019). Participants and researchers searching for meaning: Conceptual developments for interpretative phenomenological analysis, Qualitative Research in Psychology, 16(2), 166-181.

Smith, J., Flowers, P. and Larkin, M. (2009). Interpretative Phenomenological Analysis. London: Sage.

Tabor, P.D. (2011). Vicarious traumatization: Concept analysis. Journal of Forensic Nursing, 7(4), 203-208.

Tehrani, N. (2009). Compassion fatigue: experiences in occupational health, human resources, counselling and police. Occupational Medicine, 60 (2), 133-138.

Trippany, R.L., Kress, V.E.W., and Wilcoxon, S.A. (2004). Preventing vicarious trauma: what counsellors should know when working with trauma survivors. Journal of Counselling and Development, 82 (1), 31-37. 
Turgoose, D., Glover N., Barker C., and Maddox L. (2017). Empathy, compassion fatigue, and burnout in police officers working with rape victims. Traumatology, Vol. 23 (2), 205-213.

Turgoose, D., and Maddox, L. (2017). Predictors of compassion fatigue in mental health professionals: A narrative review. Traumatology, Vol. 23 (2), 172-185.

Turnbull, P. J., and Wass, V. (2015). Normalizing extreme work in the Police Service? Austerity and the inspecting ranks. Organization, 22(4), 512-529.

Van Deusen, K.M. (2006). Vicarious trauma: An exploratory study of the impact of providing sexual abuse treatment on clinicians' trust and intimacy. Journal of Child Sexual Abuse, 15(1), 60-85.

Versola-Russo, J.M. (2006). Workplace violence: vicarious trauma in the psychiatric setting. Journal of Police Crisis Negotiations, 6(2), 79-103.

Wheeler, S. and Richards, K. (2007). The impact of clinical supervision on counsellors and therapists, their practice and their clients. A systematic review of the literature. Counselling and Psychotherapy Research, 7(1), 54-65.

WHO (2019). Burnout an Occupational Phenomenon: International Classification of Diseases. Available at https://www.who.int/mental_health/evidence/burn-out/en/

Wright, R., Powell, M.B. and Ridge, D. (2006). Child abuse investigation: an in-depth analysis of how police officers perceive and cope with daily work challenges.

Policing-an International Journal of Police Strategies and Management, 29(3), 498512 
Appendix: IPA analysis guidelines

Using Smith et al (2009), the researcher engages with the original data by listening at least once to the audio-recordings of each participant while also exploring line-by-line individual transcripts. Initial thoughts and reactions are noted at the end of the selfreflection notes made after each interview. Following this stage, the researcher undertakes an intense and detailed noting, using the template provided in Smith et al. (2009). Exploratory descriptive, linguistic and conceptual comments are noted in the column on the right of the original transcript. The conceptual annotations include interpretative elements of the researcher's own reflection, but attention is given so that this level of coding remains close to the participant's words and experiences. Text that appears important at this stage is underlined and comments are recorded on the margin of the transcript.

The next stage leads to the development of emergent themes recorded in the left column next to the original transcript. These themes use the exploratory data to note relations and patterns between exploratory notes and the researcher's further interpretative processes. The themes are then written on separate pieces of paper to enable the researcher to explore connections and differences. They are then typed and clustered around. A table of super-ordinate themes and themes from the participant is then produced using the template in Smith et al (2009).

The process is then repeated for each individual case. Once completed, the researcher prints each table and starts a cross-case analysis by exploring patterns and divergences across cases. A master table of themes for the group of participants is produced with the focus of the analysis moving from individual to group emergent themes. The researcher keeps an IPA focus by illustrating each group theme with detailed examples taken from individual cases. Following this step, the emphasis shifts towards recurrent themes with the researcher moving between individual experiences and group recurrences. The analytical process continues during the writing up stage. The final master of table of group themes is then used to present key findings. 